\title{
A POSSIBILIDADE DE ADOÇÃO DO SISTEMA PARLAMENTARISTA NO BRASIL
}

\author{
Lucas Ferreira Furlan \\ Universidade do Oeste Paulista - UNOESTE, Curso de Direito, Presidente Prudente, SP. Email: \\ lucasfurlan94@hotmail.com
}

\begin{abstract}
RESUMO
Diante da grave crise política pela qual passa o país, o presente artigo tem como objetivo analisar a eventual possibilidade da adoção do sistema parlamentarista na república brasileira, iniciando-se com um breve panorama histórico da evolução do sistema, bem como, demonstrando quais seriam suas principais vantagens, o artigo busca apresentar como o referido sistema de governo se apresentaria frente às peculiaridades do Brasil, buscando se analisar se sua eventual adoção poderia a vir auxiliar na superação da crise e no aprimoramento de nossas instancias políticas. Para chegar-se ao resultado buscado será utilizado como paradigma a adoção do sistema durante a vigência da Constituição de 1946, de forma a demonstrar quais seriam os eventuais mecanismos a serem adotados com o referido modelo.
\end{abstract}

Palavras - chave: Eleições, Mandado, Parlamento, Sistemas e Representatividade.

\section{THE PARLIAMENTARY SYSTEM ADOPTION OF THE POSSIBILITY IN BRAZIL}

\begin{abstract}
Given the serious political crisis now facing the country, this article aims to analyze the eventual possibility of adoption of the parliamentary system in the Brazilian republic, beginning with a brief historical overview of the evolution of the system as well, demonstrating that their would main advantages, the article seeks to present as said system of government would present front of the peculiarities of Brazil, seeking to analyze whether their eventual adoption could come to assist in overcoming the crisis and improve our policies instances. To get to the sought result will be used as a paradigm the adoption of the system for the duration of the 1946 Constitution, in order to demonstrate what would be the possible mechanisms to be adopted with that model.
\end{abstract}

Keywords: Elections, Warrant, Parliament, Systems and Representativity. 


\section{INTRODUÇÃO}

O Brasil passa atualmente por uma das mais graves crises de sua história, ante este fato, torna-se necessário o debate quanto a eventuais caminhos a serem traçados, para buscar-se as possíveis soluções para crise instaurada. Nos últimos anos, muito tem se debatido quanto a possibilidade da realização de uma reforma polícia no país.

Os adeptos de reformas mais aprofundadas passaram a defender a mudança do sistema de governo, argumentado que a adoção do sistema parlamentarista auxiliaria no aprimoramento democrático do país, tendo em vista este possuir, mecanismos mais ágeis para a solução das adversidades políticas. $O$ presente artigo tem como objetivo discorrer de maneira sucinta sobre o histórico e as características do referido, bem como, das vantagens e desvantagens de sua adoção no Brasil, de maneira a contribuir com o debate a respeito do tema.

\section{METODOLOGIA}

$\mathrm{O}$ artigo foi norteado por pesquisas bibliográficas, leituras e fichamentos. Os dados foram analisados com emprego do método hipotético-dedutivo, informações coletadas analisadas e confrontadas de forma dialética.

\section{RESULTADOS}

Os resultados alcançados com a presente pesquisa foram concretos, de forma a contribuir de modo racional e equilibrado para o debate de eventuais caminhos para à solução da crise política no Brasil.

\section{DISCUSSÃO}

\section{A EVOLUÇÃO HISTÓRICA DO PARLAMENTARISMO}

Diante da grave crise de confiança que se abateu sobre o governo é impossível inexistir o questionamento sobre a possibilidade de adoção do sistema parlamentarista de governo no Brasil, visto que este proporciona por sua própria natureza uma mudança relativamente rápida e em tese tranquila as eventuais crises governamentais que possam vir a surgir, combatendo com isto a inevitável paralisia que se impõe ao país nestes períodos.

Quanto à origem do Sistema Parlamentarista, teceremos algumas rápidas considerações, atendendo a síntese que se faz necessária aos objetivos do presente estudo. Destaca-se os ensinamentos de José Geraldo Brito Filomeno, em sua obra, Manual de Teoria geral do Estado, (2014, cap. 19.4.1):

E, sem dúvida alguma, seu berço é a Inglaterra que, mesmo antes da invasão normanda de 1066, já estabelecera o gérmen do que seria, séculos mais tarde, o "sistema parlamentar de governo", ou também chamado de "governo de gabinete", com diversas variações, quando de sua cópia do modelo original.

O Sistema Parlamentarista se moldou ao longo da história, por influência do acaso e das pressões exercidas pela sociedade inglesa que exigia a limitação dos poderes absolutos de seus monarcas. Inicialmente a própria monarquia inglesa passou a consultar a nobreza a respeito das decisões de Estado, não com o intuito de com estes fracionar seus poderes, mas sim de manter-se aliada dos Senhores Feudais que eram indispensáveis a manutenção da Inglaterra, pois forneciam a Corte recursos de toda a sorte. Assim aos poucos foi sendo formado o chamado Conselho do Rei, sendo que este aos poucos foi dividido em dois grupos, originando a formação bicameral do parlamente inglês.

Posteriormente a ascensão de João Sem Terra ao trono, fez com que o Parlamento ganhasse novas prerrogativas, tendo sido pressionado pelos Senhores Feudais que exigiam a 
limitação dos poderes do monarca, o novo rei outorgou a Magna Carta, que entre outras garantias, determinou que membros do Parlamento tivessem a prerrogativa de analisar a imposição de novos impostos.

Posteriormente o monarca inglês passou a convocar um grupo restrito de conselheiros com os quais debatia e decidia a questões do Estado, criando o cerne daquilo que seria no futuro Gabinete de Ministros, tendo este ganhando relevante importância nos reinados da Dinastia Stuart.

O último monarca dos Stuarts faleceu sem deixar um herdeiro legítimo, assim a Casa de Hanover foi considerada herdeira legítima do trono britânico. Ocorre que os monarcas desta Dinastia não possuíam conhecimentos aprofundados das questões do reino não falando sequer o idioma inglês, com isto os Reis Jorge I e Jorge II, respectivamente primeiro e segundo monarca da Dinastia Hanover, passaram a destacar um membro do Gabinete de Ministros para lhes informar as questões debatidas e decididas pelo Gabinete, criando-se, portanto, a figura do Primeiro Ministro, que posteriormente seria elevado à condição de Chefe de Governo.

Após estas rápidas, mas necessárias considerações históricas, a respeito do Sistema Parlamentarista; passa-se a analisar a possibilidade de sua adoção no Brasil, sabendo que este já foi adotado por nossa república em um curto espaço de tempo no passado, imperiosa se torna analise desse fato, para o bom andamento do estudo, o que será feito no próximo tópico.

\section{A EMENDA PARLAMENTARISTA DE 1961}

A Emenda Constitucional $n^{\circ} 4$ de 1961, implantou o Sistema Parlamentarista no Brasil, com o objetivo de solucionar a crise institucional gerada pelo renuncia do então Presidente da República, Janio Quadros, e permitir a posse do então vice-presidente João Goulart, assim, o chefe de governo passou a ser o primeiro-ministro. $O$ vice-presidente assumiu a presidência, mas com poderes limitados.

De inicio, destacam-se os artigos $1^{\circ}$ e $2^{\circ}$ da Emenda Parlamentarista de 1961, que assim dispunham:

Art. 1으 O Poder Executivo é exercido pelo Presidente da República e pelo Conselho de Ministros, cabendo a êste a direção e a responsabilidade da política do govêrno, assim como da administração federal.

Art. 2ㅇ O Presidente da República será eleito pelo Congresso Nacional por maioria absoluta de votos, e exercerá o cargo por cinco anos.

Como se pode perceber, com a adoção do Sistema Parlamentarista, o Poder Executivo passo a ser exercido pelo Presidente da República e pelo Conselho de Ministros, sendo que a estes cabiam a chefia de governo, como é inerente ao sistema parlamentar de governo o Legislativo passará a protagonizar o sistema político, cabendo a este a escolha do Presidente da República, que voltará a possuir um mandato de cinco anos.

As funções do Presidente da República foram estabelecidas pelo artigo terceiro da Emenda Parlamentarista, sendo que todos estes eram basicamente referentes chefia de Estado, a intervenção mais significativa que Presidente possuía junto a Chefia de Governo era a prerrogativa de nomear o Chefe do Conselho de Ministros, sendo que esta nomeação posteriormente deveria ser aprovada pela maioria absoluta dos membros da Câmara dos Deputados.

Neste sentido, dispunha o artigo $3^{\circ}$, inciso I, bem como, o $8^{\circ}$ da Emenda Parlamentar de 1961:

Art. 3을 Compete ao Presidente da República:

I - nomear o Presidente do Conselho de Ministros e, por indicação dêste, os demais Ministros de Estado, e exonerá-los quando a Câmara dos Deputados Ihes retirar a confiança; 
Art. 8o O Presidente da República submeterá, em caso de vaga, à Câmara dos Deputados, no prazo de três dias, o nome do Presidente do Conselho de Ministros. A aprovação da Câmara dos Deputados dependerá do voto da maioria absoluta dos seus membros.

Parágrafo único. Recusada a aprovação, o Presidente da República deverá, em igual prazo, apresentar outro nome. Se também êste fôr recusado, apresentará no mesmo prazo, outro nome. Se nenhum fôr aceito, caberá ao Senado Federal indicar, por maioria absoluta de seus membros, o Presidente do Conselho, que não poderá ser qualquer dos recusados.

Caso a Câmara dos Deputados recusa-se o nomeado pelo Presidente para Chefia dos Ministros, trazia o parágrafo único do artigo $8^{\circ}$ da Emenda os procedimentos a serem adotados, pelo positivado, o Presidente poderia indicar ainda mais dois nomes, caso nenhum destes fosse aprovado, caberia ao Senado Federal indicar por meio de maioria de seus membros o novo Presidente do Conselho, sendo vedado qualquer dos nomes já recusados pelos deputados.

Da leitura dos dispositivos destacados, ainda se percebe a possibilidade de queda do governo nos casos de voto de desconfiança da Câmara dos Deputados, clássica característica do Sistema Parlamentarista, que veio prevista no artigo $3^{\circ}$, inciso I, da Emenda Constitucional em estudo.

Em relação ao Conselho de Ministros, destacam-se os artigos $7^{\circ}$ e $8^{\circ}$ da Emenda Constitucional Parlamentar de 1961:

Art. 60 O Conselho de Ministros responde coletivamente perante a Câmara dos Deputados pela política do govêrno e pela administração federal, e cada Ministro de Estado, individualmente pelos atos que praticar no exercício de suas funções.

Art. 70 Todos os atos do Presidente da República devem ser referendados pelo Presidente do Conselho e pelo Ministro competente como condição de sua validade.

Da leitura destes dispositivos, nota-se a vinculação que Gabinete de Ministros tinha junto aos parlamentares, tendo de responder perante estes, a respeito de temas relacionados a política de governo, administração federal, bem como, demais atos praticados no exercício de suas funções. Também se percebe o profundo esvaziamento dos poderes do Presidente da República, já que todos os atos por este praticados passaram a ter de ser referendados pelo Presidente do Conselho, como também, pelo Ministro competente, para ser validado.

Quanto à formação e manutenção do governo, analisemos os artigos $9^{\circ}$ e 10 da Emenda Parlamentarista:

Art. 9o 0 Conselho de Ministros, depois de nomeado, comparecerá perante a Câmara dos Deputados, a fim de apresentar seu programa de govêrno.

Parágrafo único. A Câmara dos Deputados, na sessão subseqüente e pelo voto da maioria dos presentes, exprimirá sua confiança no Conselho de Ministros. A recusa da confiança importará formação de novo Conselho de Ministros.

Art. 10. Votada a moção de confiança, o Senado Federal, pelo voto de dois terços de seus membros, poderá, dentro de quarenta e oito horas, opor-se à composição do Conselho de Ministros.

Parágrafo único. $\mathrm{O}$ ato do Senado Federal poderá ser rejeitado, pela maioria absoluta da Câmara dos Deputados, em sua primeira sessão. 
Pelo disposto, uma vez nomeado o Conselho de Ministros, este deveria apresentar seu programa de governo junto a Câmara dos Deputados, sendo que os parlamentares poderiam por maioria simples recusar confiança ao programa apresentado, o que implicaria na formação de um novo governo.

O Senado Federal poderia opor-se a formação do Conselho, porém teria de se manifestar neste sentido, pelo voto de dois terços de seus membros, sendo que a oposição do Senado ainda poderia ser rejeitada pela deliberação da maioria absoluta dos membros da Câmara dos Deputados.

Em relação à eventual moção de desconfiança emitida pela Câmara dos Deputados, bem como, os procedimentos a serem adotados em decorrência dos fatos que dela viessem a se suceder, dispunham os artigos 12, 13 e 14, da Emenda Constitucional Parlamentarista de 1961:

Art. 12. A moção de desconfiança contra o Conselho de Ministros, ou de censura a qualquer de seus membros, só poderá ser apresentada por cinqüenta deputados no mínimo, e será discutida e votada, salvo circunstância excepcional regulada em lei, cinco dias depois de proposta, dependendo sua aprovação do voto da maioria absoluta da Câmara dos Deputados.

Art. 13. A moção de confiança pedida à Câmara dos Deputados pelo Conselho de Ministros será votada imediatamente e se considerará aprovada pelo voto da maioria dos presentes.

Art. 14. Verificada a impossibilidade de manter-se o Conselho de Ministros por falta de apoio parlamentar, comprovada em moções de desconfiança, opostas consecutivamente a três Conselhos, o Presidente da República poderá dissolver a Câmara dos Deputados, convocando novas eleições que se realizarão no prazo máximo de noventa dias, a que poderão concorrer os parlamentares que hajam integrado os Conselhos dissolvidos.

$\S 1$ 을 Dissolvida a Câmara dos Deputados, o Presidente da República nomeará um Conselho de Ministros de caráter provisório.

§ 2ㅇ A Câmara dos Deputados voltará a reunir-se, de pleno direito, se as eleições não se realizarem no prazo fixado.

§ 3ㅇ Caberá ao Senado, enquanto não se instalar a nova Câmara dos Deputados, as atribuições do art. 66, números III, IV e VII da Constituição.

Da redação dos citados artigos, percebe-se que o Conselho de Ministros possuía a prerrogativa de solicitar moção de confiança aos parlamentares que igualmente a de desconfiança seria considerada aprovada pelo voto da maioria absoluta dos membros da Câmara dos Deputados.

Ainda, foi positivada a possibilidade de o Presidente da República dissolver a Câmara dos Deputados, em caso de três Conselhos serem consecutivamente derrubados por moções de desconfianças; sendo então convocadas novas eleições parlamentares. Até a eleição dos novos deputados seria escolhido um Conselho Provisório e o Senado assumiria algumas prerrogativas da Câmara dos Deputados.

O parlamentarismo durou pouco. Implantado em 1961, foi rejeitado no plebiscito de 1963, no qual aproximadamente $80 \%$ dos eleitores disseram "não" ao referido sistema, encerradas essas considerações, no próximo tópico irá de debater quis seriam as vantagens e desvantagens de uma eventual nova adoção do parlamentarismo no Brasil. 


\section{OS EVENTUAIS RESULTADOS DO PARLAMENTARISMO NO BRASIL ATUAL}

Como já foram detalhadas as principais características do parlamentarismo quando falamos a respeito da Emenda Parlamentarista de 1961, utilizaremos esta de paradigma para analisar as possíveis vantagens e desvantagens de uma nova implantação do deste sistema de governo no Brasil.

Uma das principais vantagens do sistema seria o fracionamento de poder, com a divisão da Chefia e Estado e de Governo em mandatários distintos, nossa República perderia a característica imperial de máxima concentração de prerrogativas e influências em uma única figura. Favorecendo inclusive o funcionamento da máquina pública, já que com funções mais delimitadas, teriam tanto o Presidente quanto o Primeiro Ministro maior disponibilidade para dedicar-se as suas competências.

Outro ponto positivo do parlamentarismo é a subordinação que os Ministros de Estado possuem em relação ao parlamento. Sendo que este pode destituir os ministros do cargo, com a aprovação da moção de desconfiança, esta característica do sistema sem dúvidas força que os auxiliares do Chefe de Governo busquem o maior desempenho possível no exercício de suas funções. Acabando com a figura dos Ministros decorativos, que muitas vezes em nosso presidencialismo de coalizão, são nomeados apenas para dar representatividade a partidos políticos no governo.

Por fim, no Sistema Parlamentarista o cerne do poder da República está no Parlamento, órgão genuíno da representação popular. Assim possui o Sistema, ao menos em tese, uma maior agilidade para oferecer respostas às demandas da sociedade, como também, possui o Parlamentarismo rápidos mecanismos para a solução de instabilidades políticas, visto existir a possibilidade de exoneração da Chefia de Governo pela moção de desconfiança emitida pelos parlamentares, como também a possibilidade de dissolução do parlamento pelo Chefe de Governo.

Contudo, pode ser temerária a adoção do Sistema Parlamentarista no Brasil sem antes a realizar-se uma reforma política no país. Como dito no início do tópico o sistema parlamentarista é originário da Inglaterra, o sistema bipartidário inglês favorece uma tranquila composição de forças no parlamento, visto que obrigatoriamente um único partido obterá no pleito a maioria das cadeiras.

Porém no Brasil a situação é completamente inversa, nosso sistema partidário fracionou-se a um ponto crítico, no qual está cada vez mais difícil formar-se uma maioria parlamentar no Congresso Nacional. Assim a implementação do Sistema Parlamentar no Brasil sem antes solucionar esta questão, poderia trazer ainda mais instabilidade política ao país, visto que as composições formadas no Congresso poderiam não conseguir dar sustentação ao governo justamente pelo excesso de partidos no parlamento.

Apesar do exposto, ainda é necessário tecer considerações quanto à constitucionalidade da adoção do Sistema Parlamentarista no Brasil. Sendo uma das características do Sistema a escolha do Chefe de Governo por meio do Parlamento, poderia este vir a esbarrar na cláusula pétrea referente ao voto direito. É evidente que caso eventualmente a proposta de adoção do Sistema venha a ganhar corpo, um debate jurídico aprofundado precise ser feito a respeito especificamente deste ponto.

Quanto à questão do sufrágio direito, é sabido não ser esta uma regra constitucional sem exceções, neste sentido destaca-se o posicionamento de Alexandre de Moraes, em seu Curso de Direito Constitucional (2012, p. 244):

Os eleitores elegerão, no exercício do direito de sufrágio, por meio do voto (instrumento), por si, sem intermediários, seus representantes e governantes. Discordamos de José Afonso da Silva que afirma que essa é uma regra sem exceções, própria a própria Constituição Federal prevê, 
excepcionalmente, no art. $81, \S 2^{\circ}$, uma espécie de eleição indireta para o cargo de Presidente da República.

É evidente que da simples leitura do mecanismo constitucional não se extrairá a solução para a questão, será necessário um debate aprofundado a respeito do tema, com o indispensável pronunciamento do Supremo Tribunal Federal, órgão responsável pela guarda da Constituição da República.

\section{CONCLUSÃO}

Encerrado o levantamento objetivado, podemos concluir que o presente artigo cumpriu com o seu objetivo inicial, contribuindo para busca de soluções para o atual impasse político pelo qual passa o país. É evidente que somente estas modestas linhas não serão capazes de apresentar uma solução robusta, mas comportada suas limitação, acredita-se que foi deixada alguma contribuição.

Uma eventual substituição do sistema de governo, não pode vir desacompanhada de um ramificado debate, no qual as mais diversas camadas da sociedade possam opinar a respeito, mesmo por que é isso o que se espera de uma República.

Desta feita, é fundamental que trabalhos como esse sejam realizados, de forma a engajar a sociedade na busca de uma solução para crise política, que venha acompanhada de um novo ciclo de aprimoramento de nossas instanciais democráticas.

\section{REFERÊNCIAS}

BRASIL. Constituição (1946). Constituição dos Estados Unidos do Brasil. Rio de Janeiro: Senado Federal, 1946.

DALLARI, D. A. Sistemas Eleitorais. In: DALLARI, D. A. Elementos da teoria geral do estado. São Paulo: Saraiva. 2013. P. 190-197.

FILOMENO, B. G. J. Manual de teoria geral do estado, 9 ed. Rio de Janeiro: Forense, 2015. Disponível em: https://integrada.minhabiblioteca.com.br/\#/books. Acesso em: jul. 2016.

LENZA, P. Direitos Políticos. In: LENZA, P, Direito constitucional esquematizado. São Paulo: Saraiva, 2014. p. 1.239.1.263.

MORAES, A. Direitos Políticos. In: Morais, A. Direito constitucional. São Paulo: Atlas, 2012. p. 239284.

NOVELINO. M. Sistemas Eleitorais. In: NOVELINO. M. Manual de direito constitucional. Rio de Janeiro: Gen. Método. 2013. P. 679-691.

BRASIL. Emenda Constitucional n4, de 02 de setembro de 1961. Diário Oficial da União, Brasília, DF, 02 set.. 1961. Disponível em: http://www2.camara.leg.br/legin/fed/emecon/19601969/emendaconstitucional-4-2-setembro-1961-349692-publicacaooriginal-1-pl.html. Acesso em: 05 jul. 2016. 